p-ISSN 1693-9484, $e$-ISSN : 2621-8313

Majalah Ilmiah Bahari Jogja (MIBJ)

Vol. 17 No. 2, Juli $2019 \quad$ (91-97)

DOI : 10.33489/mibj.v17i2.213

(C) 2019 Akademi Maritim Yogyakarta

\title{
Pencegahan Korosi Kapal Dengan Metode Pengecatan
}

\author{
Salim ${ }^{*}$ \\ ${ }^{1}$ Teknika, Akademi Maritim Yogyakarta, Jl. Magelang KM 4.4, Yogyakarta 55284, \\ Indonesia \\ * Corresponding Author. Email: salimtawang@ gmail.com. Hp 081329544038
}

\begin{abstract}
Abstrak
Salah satu sumber kerusakan terbesar pada kapal laut dan alat-alat apung lainya adalahkorosi yang disebabkan kendaraan/alat apung tersebut berada di lingkungan air laut. Kelalaian atau kekurang sempurnaan perlindungan terhadap serangan korosi air laut akan sangat merugikan. Salah satu cara untuk mengurangi kerugian yang lebih besar akibat serangan korosi tersebut adalah dengan cara pencegahan pasif. Pencegahan pasif tersebut adalah dengan cara pengecatan. Pengecatan kapal/alatapung ini bertujuan untuk menyulitkan atau menghambat terjadinya gejala-gejala tumbuh dan berkembangnya terjadinya korosi.

Pelaksaan pengecatan kapal dilakukan dalam dua (2) tahap kegiatan yaitu pembersihan badan kapal dan dilanjutkan pengecatan. Baik buruknya hasil pengecatan tergantung dari kualitas material bahan kapal, kualitas cat, jenis dan cara pembersihan kontruksi, jenis dan cara pengecatan serta ketrampilan dan pengalaman tukang cat.

Hasil pengecatan akan berpengaruh terhadap kemampuan cat dalam melindungi kontruksi kapal terhadap serangan korosi air laut.
\end{abstract}

\section{Kata Kunci : Korosi, Pencegahan Pasif dan Pengecatan}

\begin{abstract}
One of the biggest sources of damage to ships and other floating devices is corrosion caused by floating vehicles / tools in the sea water environment. Negligence or lack of perfection of protection against seawater corrosion attacks will be very detrimental. One way to reduce greater losses due to corrosion attacks is by passive prevention. Passive prevention is by painting. Painting the vessel / floating tool aims to complicate or inhibit the occurrence of symptoms of growth and development of the occurrence of corrosion.

Implementation of ship painting is carried out in two (2) stages of activities, namely cleaning the ship's body and continuing painting. The good quality of the painting depends on the quality of the material of the vessel, the quality of the paint, the type and method of cleaning the construction, the type and manner of painting and the skills and experience of the painters.

Painting results will affect the ability of paint to protect ship construction against seawater corrosion attacks.
\end{abstract}

Keyword :Corrosion, passive prevention and painting 


\section{PENDAHULUAN}

Mengingat sebagian besar wilayah Indonesia tardiri dari ribuan pulau dan disatukan oleh lautan, maka peran kapal sebagai alat transportasi menjadi suatu keharusan. Dengan jumlah pulau yang jumlahnya berkisar 15.000 buah ini, akan membutuhkan kapal dan alat apung lainnya yang sebanding. Kapal dan alat apung lain tersebut perlu dirawat dan diperbaiki agar umur pakainya sesuai standar opersional. Bentuk perawatan satu diantaranya adalah dengan pengecatan. Pengecatan adalah cara yang umum digunakan untuk mencegah kerusakan yang disebabkan oleh korosi.Korosi air laut merupakan penyebab kerusakan terbesar pada kapal laut dan alat-alat apung lainnya.Selain air laut mengandung garam yang relating tinggi, juga dalam penggunaan bahan kontruksi kapal masih didominasi dari besi atau baja sebagai bahan utama dalam pembuatan kapal. Dari segi biaya dan kekuatan penggunaan besi dan baja untuk bangunan kapal memang cukup beralasan serta memadai. Tetapi berdasarkan pengalaman besi/baja sangat reaktif dan mempunyai kecenderungan yang besar terhadap korosi dari air laut.

Untuk itu sudah merupakan suatu kewajiban bagi para stake holder di bidang perkapalan untuk berusaha melindungi kapal-kapal tersebut dari serangan korosi air laut. Ketidak disiplinya perawatanterhadap serangan korosi air laut akan sangat merugikan. Karena korosi pada kontruksi kapal akan mengakibatkan turunnya kekuatan dan umur pakai kapal, yang berakibat akan mengurangi kecepatan serta mengurangi jaminan keselamatan serta keamanan muatan barang dan penumpang.

Perawatan dan pemeliharaan kapal secara terus - menerus harus dilakukan serta benar-benar diperhatikan. Kapal yang tidak naik dok secara teratur akan mengalami kerusakan akibat korosi air laut yang semakin berat dan berlanjut.

Salah satu cara untuk melindungi dari ganasnya serangan korosi dari air laut adalah dengan cara pengecatan. Pengecatan adalah cara perlindungan secara pasif. Perlindungan ini hanya bertujuan menyulitkan terjadinya proses korosi. Mengingat pengecatan merupakan suatu carapencegahan yang umum dilakukan.

\section{Pengertian Korosi}

Menurut NACE (National Association of Corrosion Engineer) mengartikan korosi sebagai penurunan mutu suatu material (baja) atau sifat-sifatnya yang diakibatkan oleh reaksi dengan lingkunganya, Sedangkan Trethewey, 1998, mengatakan korosi sebagai penurunan mutu baja akibat reaksi elektrokimia dengan lingkungannya.

ASM Material Engineering Dictionary mengatakan korosi sebagai reaksi kimia atau elektrokimia antara anoda dan katoda baja dengan lingkungan elektrolit yang berakibat pada penurunan mutu material dan sifat kimianya.

Korosi adalah peristiwa turunya kemampuan material logam menerima beban, sebagai akibat terjadinya peristiwa oksidasi dengan lingkungan yang mengalami penipisan material dari kontruksi. Zulfaidah A., 2014.

Korosi pada kontruksi kapal tidak dapat dihilangkan tetapi hanya diperlambat perkembangannya. Korosi dapat menyebabkan menurunya kekuatan plat lambung kapal, mengurangi kecepatan kapal, serta mengurangi jaminan keselamatan dan keamanan muatan dan penumpang, Tri Karyono, dkk. 2017. Korosi dikelompokan menjadi 2 yaitu korosi basah yang disebabkan oleh karena lingkungan yang 
mengelilinginya mengandung suatu larutan dan korosi kering dikarenakan reaksi dari gas dalam temperatur tinggi.

\section{Faktor - faktor yang menimbulkan korosi}

\section{Sifat logam :}

a) Pengaruh susunan kimia pada logam, selain Fe sebagai unsur dasar masih ada unsur lain seperti C, Si, Mn, Ni, S dan P. Khususnya C, Mn, S dan P yang berpengaruh terhadap timbulnya korosi air laut pada pelat badan kapal.

b) Pengaruh Mill Scale. Susunan mill scale terdiri dari 3 (tiga) lapisan yaitu : lapisan terluar adalah $\mathrm{Fe}_{2} \mathrm{O}$, lapisan tengah terdiri dari $\mathrm{Fe}_{3} \mathrm{O} 4 d a n \mathrm{FeO}$, sedangkan lapisan yang berdekatan denganpelat baja kapal terdiri dari $\mathrm{FeO}$ dan Fe.

Dari beberapa lapisan ini menimbulkan rekasi kimia yang berakibat perbedaan beda potensial antara pelat baja kapal. Oleh karena itu dengan adanya perbedaan potensial elektro kimia seperti tersebut,Terjadilah suatu reaksi yang menimbulkan terjadinya korosi air laut pada pelat baja kapal. Terdapat $\mathrm{Fe}_{3} \mathrm{O}_{4}$ pada hasilkorosi pada plat baja kapal akan menimbulkan daerah anoda yang akan terus meluas sampai dibawah lapisan mill scale. Daerah anoda yang kedua ini menimbulkan korosi air laut yang lebih besar dibandingkan dengan anoda yang pertama, karena oksigen bebas dapat bereaksi.

\section{Sifat Fisika - Kimia air laut}

Sifat Kimia - Fisika air laut dengan kadar garam yang relative besarmenentukan penghantaran listrik pada air laut. Sedangkan kemampuan penghantaran listrik oleh air laut merupakan salah satu factor yang mempercepat terjadinya proses korosi. Perubahan daya hantar air laut tergantung dari kadar garam dan temperature. Pada kadar garam yang sama, dengan makin tinggi temperature air laut makintinggi pula daya hantar listrik air laut.Sedangkan pada temperature air laut yang sama, dengan makin besar kadar garam air laut maka makin besar pula daya hantar listrik air laut. Jadi apa bila suatu kapal memasuki muara sungai yang mempunyai kadar garam lebih rendah, sehingga mengakibatkan proses korosi lebih lambat apa bila dibandingkan dengan proses korosi pada air laut bebas. Menurut Satria N., dkk, 2012 mengatakan bahwa setiap penambahan salinitas 3 \%o maka laju korosi rata-rata bertambah sebesar 0,0415 mmpy.

\section{Sifat biologis air laut}

Melekatnya binatang dan tumbuh - tumbuhan laut pada pelat badan kapal, akan memperbesar tahanan kapal sehingga memperkecil kecepatan kapal dan dengan demikian berarti akan memperbesar pemakaian bahan bakar, ternyata juga menimbulkan terjadinya korosi air laut pada pelat badan kapal.

Proses melekatnya binatang dan tumbuh-tumbuhan laut yang menimbulkan korosi pada pelat badan kapal adalah sebagai berikut :Pada permukaan pelat badan kapal melekat mikro organisme ber sel satu. Hal ini terjadi karena dengan pertolongan zat perekat cat, mikro organisme ber sel satu tersebut melekat pada lapisan cat badan kapal, sehingga terjadi lapisan yang mudah melepas. Pada lapisan yang mudah terlepas tersebut kemudian timbul benih-benih binatang laut dan sporaspora, sehingga binatang dan tumbuhan laut tersebut dapat berkembang dengan 
baik. Pengaruh langsung dari mikro organisme ber sel satu adalah bahwa pada permukaan zat akan menghasilkan zat-zat yang agresif seperti $\mathrm{NH}_{4} \mathrm{OH}, \mathrm{CO}_{2}, \mathrm{H}_{2} \mathrm{~S}$ dan atom-atom yang agresif pula. Selanjutnya akibat reaksi elektro kimia terjadilah gas oksigen. Gas oksigen ini karena pengaruh chlorophile akan membentuk kembali sulfit yang akan menghasilkan zat yang berpengaruh terhadap terjadinya korosi air laut.

Untuk itu maka binatang dan tumbuhan laut yang melekat pada plat badan kapal secara teratur harus dihilangkan. Karena semakin lama akan semakin melekat pada badan kapal dan akan bertambah besar serta proses korosi air laut pada plat badan kapal akan semakin besar.Selainitu semakin lama kapal berada di tambatan (kapal tidak bergerak) akan mempercepat proses melekatnya binatang dan tumbuhan laut pada badan kapal, sehingga akan menimbulkan terjadinya korosi air laut.

a. Jenis - jenis korosi yang merusak bagian - bagian kapal(Trikaryono, dkk.2017) :

1. Korosi merata/seragam (Uniform Corrosion) yaitu seluruh permukaan material diserang oleh korosi di wilayah yang luas (Benjamin D. Craig, 2006)

2. Korosi Sumuran merupakan korosi yang muncul dan terkonsentrasi pada daerah tertentu. Perlobangan yaitu pada permukaan material terjadi lobang - lobang yang semakin lama smakin dalam

3. Korosi Tegangan (Stress Corrosion) yaitu terjadi pada kontruksi yang memikul beban besar. Mamlu (2001) menyatakan besarnya beban penekanan pada besi beton sebelum mengalami proses korosi akan sangat berpengaruh sekali terhadap laju korosi yang terjadi pada besi tersebut. Bahwa semakin besar penekanan (pemberian beban) yang diberikan pada spesimen maka laju korosi yang terjadi akan semakin besar.

4. Korosi Erosi (Erosion Corrosion) yaitu terjadi pada material yang sering menerima tumbukan pertikel - pertikel cairan yang mengalir dengan kecepatan tinggi

5. Korosi Celah (Crevice Corrosion) yaitu terjadi pada daerah - daerah jepitan, sambungan - sambungan dan daerah - daerah tertutup oleh kotoran kotoran bias binatang atau tumbuhan laut

6. Korosi Galvanis (Galvanis Corrosion) yaitu terjadi didalam air laut karena material berhubungan dengan material alin yang bersifat katodik (lebih mulia) dengan perbedaan potensial kedua material yang cukup besar.

\section{b. Bagian - bagian kapal yang Rawan Korosi}

1. Daerah antara sarat muatan kapal penuh dengan sarat muatan kosong

2. Daerah buritan kapal disekitar baling - baling dan daun kemudi kapal

3. Pada saluran - saluran pembuangan air kotor

4. Pada daerah pelat sekat kedap air

5. Pada daerah pelat geladak dibawah kamar mandi/wc dan ruang pendingin

6. Pada Sea Chest (Kotak Laut)

7. Di daerah lainya yang biasa tergenang air laut. 


\section{METODE}

Penulisan karya ilmiah ini adalah berdasarkan penelitian diskriptif yang berusaha mengemukakan dan memecahkan masalah dari kondisi kapal atau alat apung lainya yang dibuat dari bahan baja atau logam. dengan mendasarkan data baik visual, literasi. Data yang ada tersebut, selanjutnya di analisis dan diintepretasikan, yang bersifat korelatif dan komparatif (Cholid Narbuko dan Abu Achmadi)

Dalam penulisan karya ilmiah ini penulis menggunakan sumber-sumber yang berasal dari data sekunder literasi, visual, sehingga dalam mendiskripsikan tidak terlepas dari apa yang sekarang sedang berlangsung, memperkirakan kondisi yang akan datang dan membuat intepretasi sesuai dengan rumusan masalah yang menjadi bahasannya.

\section{HASIL DAN PEMBAHASAN}

\section{Pencegahan Korosi pada kapal ada dua (2) macam :}

yaitu aktif dan pasif (Pengecatan). Sebelum dilakukan pengecatan agar supaya hasil pengecatan optimal dilakukan pembersihan. Plat atau kontruksi yang akan di cat harus bersih dari kotoran agar daya lekat cat dapat maksimal. Cara pembersihan kontruksi/plat kapal dari korosi adalah sebagai berikut :

1. Pengetokan, dilakukan dengan menggunakan palu ketok

2. Penyikatan, dilakukan dengan menggunakan sikat baja, biasanya dilakukan setelah pengetokan

3. Penggerendaan, dilakukan dengan menggunakan gerinda listrik, penggerendaan ini dilakukan tidak perlu melalui pengetokan

4. Penyemprotan dengan pasir dan udara tekan (Sand Blasting), dengan tekanan sekitar $8 \mathrm{~kg} / \mathrm{Cm}^{2}$ lewat nozzle dan dengan pasir (besi, silikat, kwarsa) dengan diameter $0,5 \mathrm{~s} / \mathrm{d} 1,00 \mathrm{~mm}$

\section{Cara pengecatan ada 3 macam}

1. Dilakukan dengan menggunakan kuas

2. Dilakukan dengan menggunakan Roll

3. Dilakukan dengan menggunakan penyemprotan (Sprayer)

Pengecatan dengan menggunakan kuwas biasa akan menghasilkan luas pengecatan yang tidak begitu luas sehingga akan memakan waktu yang relative lama. Cara yang sering dilakukan adalah dengan roll,karena selain dapat menghasilkan pengecatan permukaan yang luas dan cepat. Hasil pengecatan dengan menggunakan roll ini adalah 5 - 6 kali bila dibandingkan dengan kuwas biasa. Disamping itu keuntungan bila menggunakan roll sekitar 30\% karena cat yang terbuang lebih sedikit. Untuk mendapatkan hasil pengecatan yang lebih luas dan dalam waktu yang singkat maka dapat digunakan penyemprotan (Sprayer).

Pengecatan terhadap bagian - bagian kapal , dilakukan dalam beberapa tahap . Hal ini berkaitan pelapisan cat dan ketebalan cat.Ketebalan tiap lapisan cat sangat penting yaitu untuk memperoleh hasil pengecatan yang baik.Hasil pengecatan yang terlalu tebal atau terlalu tipis harus dihindari.Ketebalan tiap lapis yang normal adalah $30 \mathrm{~s} / \mathrm{d} 50$ mikro. 
Interval tiap - tiap lapis cat tergantung dari daya pengeringnya. Lapisan cat berikutnya dapat dilakukan apa bila lapisan cat yang terdahulu sudah kering, tetapi tidak boleh melampaui batas kelonggaran cat yang sudah ditentukan, karena akan memberikan daya adhesi yang kurang baik. Interval yang diperlukan oleh masing masing cat berbeda. Cat primer waktu kelonggaranya 10 jam dan paling lama lambat 3 bulan. Cat anti korosif waktu kelonggaranya paling cepat 50 menit dan paling lama 8 jam sedang cat anti binatang dan tumbuh- tumbuhan laut waktu yangdiperlukan untuk pengecatan berikutnya 24 jam.

\section{Penggunaan Cat}

Jenis cat yang digunakan dalam pengecatan berbeda-beda sesuai dengan fungsi cat itu sendiri. Adapun jenis cat yang digunakan pada kapal antara lain :

1. Cat Primer (P), yaitu cat dasar, merupakan lapisan pertama pada permukaan. Cara ini berfungsi untuk menutup pori-pori pelat sekaligus sebagai daya scrap atau lekat dengan lapisan berikutnya.

2. Cat Anti Corrosion (AC), cat ini mempunyai sifat menahan oksidasi sehingga menahan korosi pada pelat. Umumnya digunakan pada lapisan kedua srtelah cat primer.

3. Cat Anti Fouling (AF), cat ini mempunyai sifat mengurangi daya tempel dan mematikan binatang laut, sehingga mengurangi banyaknya binatanf laut yang menempel pada waktu berlabuh. Cat ini dipergunakan pada bagian kapal antara lunas sampai dengan garis air. Dimana pada bagian ini selalu tercelup air dan sangat mungkin ditempeli binatang laut.

4. Cat Bottop (B/T), Cat bottop yaitu cat yang mempunyai daya korosif yang tinggi dan merupakan lapisan setelah anti korosi. Cat ini dipergunakan pda daerah diantara garis muat kosong dan garis muat penuh. Dimana pada daerah ini meruprakan daerah yang sangat mungkin terjadi korosi karena selalu terjadi perubahan antara tercelup air dan terkena udara.

5. Cat Top Side (T/S), cat ini dipergunakan untuk cat terahkir (finished paint) , yang dipergunakan dibagian kapal diatas garis air penuh dan warnanya disesuaikan dengan jenis kapal.

6. Cat Deck, yaitu cat yang diperunakan untuk mengecat dek, selain yang ada pada daerah tertentu, misalnya :Halt paint digunakan untuk palkah, funnel (cerobong).

7. Cat Bitominious, yaitu cat khusus untuk bagian jangkar, rantai jangkar dan chain locker (kotak jangkar).

\section{Bagian Pengecatan Kapal}

1. Pengecatan pada daerah Top Side menggunakan Cat Primer, Cat Anti Corrosion, Cat Top side.

2. Pengecatan pada daerah Bottop menggunakanCat Primer, Cat Anti Corrosion, Cat Bottop.

3. Pengecatan pada daerah Bottom menggunakan Cat Primer, Cat Anti Corrosion, Cat Anti Fouling (Kusna, 2008)

4. Pengecatan pada daerah Top Side menggunakan Cat Primer, Cat Anti Corrosion, Cat Top side. 


\section{SIMPULAN}

Penyebab kerusakan paling besar pada kapal atau alat apung yang berbahan dasar dari logam adalah kondisi lingkungan di air laut. Untuk mencegah perkembangan korosi tersebut pada umumnya dilakukan dengan cara pengecatan ataupasif. Sebelum dilakukan pengecatan dilakukan pembersihan pada bagian yang akan di cat, karena jenis - jenis korosi yang ada pada logam bermacam - macam. Jenis cat yang di catkan terdiri dari cat Primer, cat anti corrosion, cat anti Fouling, cat Bottop, cat top side. Pelaksanaan pengecatan disesuaikan dengan lokasi $\mathrm{kapal} / \mathrm{tempat}$ yang di cat dan batasan interval waktu.

\section{DAFTAR PUSTAKA}

Benjamin D. Craig, 2006, Corrosion Prevention and Control A Program Management Guide For Selecting Material, New York : AMMTIAC

Cholid Narbuko dan Abu Achmadi, 2013, Metodologi Penelitian, Bumi Aksara, Jakarta

Kenneth R. Trethewey, John Chamberlain, 1991, Korosi untuk Mahasiswa dan Rekayasawan, Terjemahan Alex Tri Kantjono Widodo, PT. Gramedia Pustaka Utama, Jakarta

Mamlu, MH, 2001, Penelitian Sifat Fisis Dan Mekanis Pada Besi Beton Yang Mendapat Beban Tekan Dan Dikorosi, Skripsi, Teknik Mesin, Teknologi Industri, Institut Sains Dan Teknologi Akprind Yogyakarta.

NACE International, 2002, Corrotion Engineer's Reference Book, Third Edition, Texas, USA

Satria Nova MK dan M. Nurul Misbah, 2012 Analisa Pengarush Salinitas dan Suhu Air Lautterhadap laju korosi Baja A36 pada Pengelasan SMAW, Jornal Teknik ITS Vol.1 September 2012

Tri Karyono, Budianto, dkk. 2017, Analisa Teknik Pencegahan Korosi Pada Lambung Kapal Dengan Variasi Sistem Pencegahan ICCP dibandingkan dengan SACP. Jornal Pendidikan Profesional, Volume 6, No. 1 April 2017

Toto Rusianto, 2009, Perubahan Laju Korosi Akibat Tegangan Dalam DenganMetode C-Ring, Jurnal Teknologi Technoscientia ISSN: 19798415,Vol. 2 No. 1 Agustus 2009134

Zulfaidah Ariany, 2014, Kajian Reparasi Pengecatan Pada Lambung Kapal, Ejournal.undip.ac.id/index.php/teknik.

ASM Handbook, Vol. V, Surface Engineering, The Material Information Sociaty. 